\title{
Surface-exposed proteins of pathogenic mycobacteria and the role of cu-zn superoxide dismutase in macrophages and neutrophil survival
}

\author{
Michael McNamara ${ }^{1,4 \dagger}$, Shin-Cheng Tzeng ${ }^{3,4 \dagger}$, Claudia Maier ${ }^{3,4}$, Martin Wu $\mathrm{u}^{1,4}$ and Luiz E Bermudez ${ }^{1,24^{*}}$
}

\begin{abstract}
Pathogenic mycobacteria are important agents causing human disease. Mycobacterium avium subsp. hominissuis (M. avium) is a species of recalcitrant environmental pathogen. The bacterium forms robust biofilms that allow it to colonize and persist in austere environments, such as residential and commercial water systems. M. avium is also an opportunistic pathogen that is a significant source of mortality for immune-compromised individuals. Proteins exposed at the bacterial surface play a central role in mediating the relationship between the bacterium and its environment. The processes underlying both biofilm formation and pathogenesis are directly dependent on this essential subset of the bacterial proteome. Therefore, the characterization of the surface-exposed proteome is an important step towards an improved understanding of the mycobacterial biology and pathogenesis. Here we examined the complement of surface exposed proteins from Mycobacterium avium 104, a clinical isolate and reference strain of Mycobacterium avium subsp. hominissuis. To profile the surface-exposed proteins of viable M. avium 104, bacteria were covalently labeled with a membrane impermeable biotinylation reagent and labeled proteins were affinity purified via the biotin-streptavidin interaction. The results provide a helpful snapshot of the surface-exposed proteome of this frequently utilized reference strain of M. avium. A Cu-Zn SOD knockout mutant, MAV_2043, a surface identified protein, was evaluated regarding its role in the survival in both macrophages and neutrophils.
\end{abstract}

Keywords: Mycobacterium avium, Surface-exposed proteome, Shotgun proteomics, Cu-Zn SOD

\section{Introduction}

Pathogenic mycobacteria are responsible for a large number of human infections. The interaction between the pathogen and the human host is complex, but surface-exposed molecules are very significant in several aspects of the interaction.

An opportunistic pathogen, Mycobacterium avium subsp. hominissuis (M. avium) rose to prominence during the HIV/ AIDS epidemic of the 1980's and 1990's [1]. M. avium is an environmental pathogen that is notable for its ability to form tenacious biofilms that allow it to persist and thrive in many environments [2]. The bacterium is also a capable pathogen that actively adheres to host tissue and invades host cells [3]. Following colonization, $M$. avium can survive and proliferate within the intra-cellular environment of host phagocytes,

\footnotetext{
*Correspondence: luiz.bermudez@oregonstate.edu

${ }^{\dagger}$ Equal contributors

'Department of Biomedical Sciences, Molecular and Cellular Biology Program, Corvallis, USA

${ }^{2}$ Department of Microbiology, Corvallis, USA

Full list of author information is available at the end of the article
}

which it hijacks as vehicles for dissemination [4]. Significant progress has been made in the understanding of $M$. avium pathogenesis, but the mechanisms that the bacterium employs to sense and interact with its environment remain largely unknown. The characterization of the surfaceexposed proteome M. avium 104, the primary reference strain for this species, is an important step in filling this gap.

The surface-exposed proteome of a bacterium is of great interest to both microbiologists and immunologists. Attachment, motility, molecular transport and conjugation are all functions that are critically dependent on proteins exposed at the surface interface. In addition, surface-expressed proteins are likely to be important to interaction with phagocyte cells $[5,6]$. Surface proteins are also primary targets for both innate and adaptive immune responses. Effective engagement of pathogens by the immune system requires the recognition of accessible targets, which tend to be surfaceexposed molecules. Accordingly, surface-exposed proteins are disproportionately represented in the antigenic profiles from mycobacteria-infected animal hosts $[7,8]$. 
There are several challenges that complicate the analysis of surface-exposed proteins. The biggest obstacle is often the selective isolation of these proteins, which represent a small fraction of the total cellular proteome. The covalent labeling of surface-exposed proteins with affinity tags using membrane-impermeable reagents, particularly biotin-based reagents, is a proven method for this type of analysis [9-11]. The primary advantage of biotinylation is the ability to selectively label surface-exposed proteins in mild, isotonic buffers. A unique challenge of this standard approach is the effective solubilization of target proteins, in buffers compatible with affinity purification, from the mycomembrane of $M$. avium, which is a durable, cross-linked and hydrophobic structure [12]. To address this issue this study utilized two experimental protein extraction buffers that are optimized be used at two different concentrations for protein extraction and affinity purification, respectively. At full strength, both buffers are effective at solubilizing and/or denaturing the total protein from whole cell lysates. Subsequently, non-solubilized debris is then removed and the samples are diluted in order to be compatible with biotin-streptavidin based affinity purification. Following purification, we employed on-bead digestion in tandem with "shotgun" mass spectrometry to characterize the surface-exposed proteome of our target bacteria, M. avium subsp. hominissuis. In total, this analysis yielded a detailed profile of the surface proteome of a clinically-relevant strain of mycobacteria, $M$. avium 104. It also offers potential targets for attenuation of the bacterial virulence as demonstrated in this study.

\section{Materials and methods}

\section{Preparation of M. avium cultures}

M. avium 104 (a clinical isolate and sequenced reference strain of Mycobacterium avium subsp. hominissuis) was grown on Middlebrook 7H10 agar and transferred into $200 \mathrm{ml}$ of Middlebrook 7H9 broth supplemented with 10\% oleic albumin dextrose catalase (OADC) (Hardy Diagnostics, Santa Maria CA) and cultured at $37^{\circ} \mathrm{C}$ with constant agitation. Exponentially growing bacteria were harvested by centrifugation $(1,500 \times g$ for $15 \mathrm{~min})$ and washed twice with WB-PBS $\left(150 \mathrm{mM} \mathrm{NaCl}, 20 \mathrm{mM} \mathrm{Na} \mathrm{HPO}_{4}, .05 \%\right.$ Tween20 (vol/vol), pH 7.2) and twice with BupH-PBS (150 mM $\mathrm{NaCl}, 100 \mathrm{mM} \mathrm{Na}_{2} \mathrm{HPO}_{4}, \mathrm{pH}$ 7.3). Bacteria were then separated into equal aliquots (approximately $100 \mathrm{mg}$ of bacteria per aliquot), pelleted and re-suspended in $1 \mathrm{ml}$ BupH-PBS.

$M$. avium transposon library was created as reported previously [13] and the mutant in the MAV_2043 gene was sequenced as reported [13]. The mutation had no effect on the ability of the clone to grow in vitro.

\section{Biotinylation M. avium surface-exposed proteins} Immediately prior to biotinylation, a fresh solution of Sulfo-NHS-LC-Biotin (LC-Biotin) (Pierce, Rockford IL) was prepared at a concentration of $1 \mathrm{mg} / \mathrm{ml}$ in $\mathrm{BupH}$ PBS. For experimental samples, $500 \mu \mathrm{l}$ of either reagent solution was added per aliquot, for a total reaction volume of $1.5 \mathrm{ml}$. For negative controls (no biotin), $500 \mu \mathrm{l}$ of BupH-PBS was added instead. The biotinylation reaction was allowed to proceed for $20 \mathrm{~min}$ at $23^{\circ} \mathrm{C}$ with gentle agitation. Upon completion of the labeling reaction, each aliquot was washed twice with BupH-PBS supplemented with glycine $(10 \mathrm{mg} / \mathrm{ml})$ and twice with plain BupH-PBS to inactivate and remove any unbound biotinylation reagent. Bacterial samples were then pelleted and the supernatant was discarded.

\section{Total protein extraction}

Bacterial samples were placed on ice and $300 \mu \mathrm{L}$ of $100 \mu \mathrm{m}$ glass beads (Sigma, St. Louis, MO) were added to each sample. Two protein extraction buffers were used in this study: Detergent Extraction Buffer (DEB) (150 mM NaCl, $20 \mathrm{mM} \mathrm{Na} \mathrm{HPO}_{4}, 0.05 \%$ Tween-20 (vol/vol), 0.1\% Triton X-100 (vol/vol), 0.2\% CHAPS [wt/ vol], $\mathrm{pH}$ 7.3) and Urea Extraction Buffer (UEB) (150 mM $\mathrm{NaCl}, 20 \mathrm{mM} \mathrm{Na} \mathrm{HPO}_{4}, 0.05 \%$ Tween-20 (vol/vol), $7 \mathrm{M}$ urea, $0.2 \%$ CHAPS [wt/vol], $\mathrm{pH}$ 7.3). Pellets of biotinlabeled M. avium were resuspended in $700 \mu$ of either DEB or UEB. Bacteria were disrupted by bead milling (6 pulses of $30 \mathrm{~s}$ ). After disruption, samples were centrifuged $(12,000 \times g$ for $15 \mathrm{~min})$ to pellet non-soluble components and supernatant was removed to a clean tube. Each sample was subjected to two rounds of protein extraction, and the resulting supernatants were pooled for a final sample volume of $\sim 1.2 \mathrm{ml}$.

\section{Analysis of endogenous biotinylation and solubilization capacity of protein extraction buffers}

To assess endogenous biotinylation and to compare the relative protein solubilization capacity of the buffers used in this study, total protein was extracted using each buffer from both biotinylated and non-biotinylated aliquots of $M$. avium. Briefly, total protein from 4 aliquots of nonbiotinylated M. avium and four aliquots of Sulfo-NHS-LCBiotin-labeled bacteria were extracted in either BupH-PBS, WB-PBS, DEB or UEB. Bacteria were disrupted with bead milling and soluble protein was isolated, as described above. Equal parts of each protein sample were separated by SDS-PAGE. Following SDS-PAGE separation, proteins were transferred to wet nitrocellulose membranes and analyzed by Western blot. IRDye-680 streptavidin (Licor, Lincoln, NE) was used to probe membranes for biotinylated proteins, following manufacturer protocol. Biotinylation patterns were visualized on an Odyssey Scanner (Licor).

Affinity purification with streptavidin-coupled Dynabeads Prior to affinity purification, $120 \mu \mathrm{l}$ aliquots of magnetic, streptavidin-coupled C1 Dynabeads (Invitrogen, Carlsbad, 
CA) were washed twice with WB-PBS using a magnetic stand. Also prior to affinity purification, each sample was diluted with 3 volumes of WB-PBS. Diluted buffers were used for subsequent affinity purification and washing steps ((DEB (dilute): $150 \mathrm{mM} \mathrm{NaCl}, 20 \mathrm{mM} \mathrm{Na} \mathrm{HPO}_{4}, 0.05 \%$ Tween-20 (vol/vol), 0.025\% Triton X-100 (vol/vol), 0.05\% CHAPS [wt/vol], $\mathrm{pH} 7.3$ ) and (UEB (dilute): $150 \mathrm{mM}$ $\mathrm{NaCl}, 20 \mathrm{mM} \quad \mathrm{Na}_{2} \mathrm{HPO}_{4}, \quad 0.05 \%$ Tween-20 (vol/vol), $1.75 \mathrm{M}$ urea, 0.05\% CHAPS [wt/vol], pH 7.3)). Each diluted protein sample was mixed with a $120 \mu$ l aliquot of Dynabeads and incubated for $60 \mathrm{~min}$ at $23^{\circ} \mathrm{C}$ with gentle agitation. After incubation, samples were washed three times with their respective affinity capture buffer (either DEB (dilute) or UEB (dilute)). Samples were then washed twice with WB-PBS and three times with ammonium bicarbonate buffer (ABB) $\left(50 \mathrm{mM} \mathrm{NH} \mathrm{HCO}_{3}, \mathrm{pH} 7.8\right)$. Each sample was then resuspended in $\mathrm{ABB}$ and split into two equal aliquots. Two of these aliquots were used for enzymatic proteolysis and the third was used to visualize the captured proteins by SDS-PAGE.

\section{Enzymatic digest of purified surface proteins}

Prior to enzymatic digestion, aliquots of Dynabeads, complexed with captured proteins, were resuspended in $50 \mu \mathrm{l}$ of ABB supplemented with $0.025 \%$ [wt/vol] ProteaseMax (Promega, Madison WI) a surfactant showed to increase the efficiency of trypsin digestion, and incubated at $37^{\circ} \mathrm{C}$ with constant agitation for $20 \mathrm{~min}$. Then, $46 \mu \mathrm{l}$ of $\mathrm{ABB}$ and $1 \mu \mathrm{l}$ of $500 \mathrm{mM}$ dithiothreitol (Sigma) was added to each aliquot, and samples were incubated at $60^{\circ} \mathrm{C}$ for $20 \mathrm{~min}$. Next, $3 \mu \mathrm{l}$ of $500 \mathrm{mM}$ iodoacetamide (Sigma) was added to each aliquot and samples were incubated in darkness for $15 \mathrm{~min}$ at $23^{\circ} \mathrm{C}$. Five $\mu \mathrm{l}$ of acetonitrile $(\mathrm{ACN})$ was added to each aliquot and samples were incubated at $37^{\circ} \mathrm{C}$ for $5 \mathrm{~min}$. For enzymatic proteolysis, each equal aliquot was digested with $1 \mu \mathrm{g}$ of either Trypsin Gold or Glu-C (Promega) for $6 \mathrm{~h}$ at $37^{\circ} \mathrm{C}$, with constant agitation. Following proteolysis, the Dynabeads were removed from the LC-Biotin-treated samples with a magnetic stand. Peptides from each aliquot were purified and desalted on C-18 reverse phase spin columns (Sartorius, Goettingen Germany), according to manufacturer instructions. Following purification, samples were dried by vacuum centrifugation and resuspended in $8 \mu \mathrm{l}$ of MS Loading Buffer (95\% $\mathrm{H}_{2} 0,4.9 \%$ $\mathrm{ACN}$ (vol/vol), 0.1\% formic acid ( $\mathrm{vol} / \mathrm{vol})$ ).

\section{Preparation of negative controls}

To detect non-specific background and endogenously biotinylated proteins, samples of $M$. avium were isolated from the conditions described above for use as negative controls. These samples were processed in the previously described manner, except with biotinylation omitted. Data from negative controls were pooled to create a master list of false positive identification and these proteins were then subtracted from the experimental data sets.

\section{LC-MS/MS analysis}

Data dependent LC-MS/MS analyses were performed on LTQ-FT Ultra mass spectrometer with IonMax ion source (Thermo) coupled to a nanoAcquity Ultra performance LC system (Waters) equipped with a Michrom Peptide CapTrap column and a C18 column (Agilent Zorbax 300SB-C18, $250 \times 0.3 \mathrm{~mm}, 5 \mu \mathrm{m})$. A binary gradient system was used consisting of solvent A (0.1\% aqueous formic acid) and solvent $\mathrm{B}$ (ACN containing $0.1 \%$ formic acid). Two $\mu \mathrm{l}$ of $\mathrm{C}-18$ column purified peptides were then trapped and washed with $3 \%$ solvent $\mathrm{B}$ at a flow rate of $5 \mu \mathrm{l} / \mathrm{min}$ for $3 \mathrm{~min}$. Trapped peptides were then eluted on to analytical column using a linear gradient from $3 \% \mathrm{~B}$ to $30 \% \mathrm{~B}$ at a flow rate of $4 \mu \mathrm{l} / \mathrm{min}$ over $35 \mathrm{~min}$. Column was maintained at $37^{\circ} \mathrm{C}$ during the run. The mass spectrometer was operated in a datadependent acquisition mode. A full FT-MS scan $(\mathrm{m} / \mathrm{z}$ 350-2000) was alternated with CID MS/MS scans of the five most abundant doubly- or triply-charged precursor ions. As the survey scan was acquired in the ICR cell, the CID experiments were performed in the linear ion trap where precursor ions were isolated and subjected to CID in parallel with the completion of the full FT-MS scan. CID was performed with helium gas at a normalized collision energy $35 \%$ and activation time of $30 \mathrm{~ms}$. Automated gain control (AGC) was used to accumulate sufficient precursor ions (target value, $5 \times 10^{4} /$ micro scan; maximum fill time $0.2 \mathrm{~s}$ ). Dynamic exclusion was used with a repeat count of 1 and exclusion duration of 60 s. Data acquisition was controlled by Xcalibur (version 2.0.5) software (Thermo).

\section{Database search}

Thermo RAW data files were processed with Proteome Discoverer version 1.2 using default parameters. A Mascot (version 2.2.04) search against whole SwissProt 2010 database (523151 sequences; 184678199 residues) or a Mycobacterium avium (strain 104) database (obtained from UniProt; 5040 sequences; 1586464 residues) was launched from Proteome Discoverer with the following parameters: the digestion enzyme was set to Trypsin/P and two missed cleavage sites were allowed. The precursor ion mass tolerance was set to $5 \mathrm{ppm}$; whereas, fragment ion tolerance of $0.8 \mathrm{Da}$ was used. Dynamic modifications included carbamidomethyl (+57.0214 Da) for Cys and oxidation $(+15.9994 \mathrm{Da})$ for Met. Lists of identified proteins from each sample were summarized by Scaffold 3 (Proteome Software, Portland OR). Inclusion of proteins in the final data set required at least two unique peptide identifications per protein and a minimum protein identification probability of $95 \%$, as calculated by Scaffold 3 . 


\section{Phagocytes}

Human monocyte-derived macrophages were purified from buffy-coat as previously described [14]. Monocytes were seeded in a 24 well tissue culture plate in presence of RPMI-1640 supplemented with 5\% fetal bovine serum and allowed to mature to macrophage in 3 days. Monolayers $\left(10^{5}\right.$ cells) were infected with $M$. avium MAV_2043 Cu$\mathrm{Zn}$ SOD KO and with M. avium MAC104 wild type (5 × $10^{5}$ cells). Monolayers were washed after $30 \mathrm{~min}$ and the number of intracellular bacteria determined after lysis of the monolayer [14] at 1 and 2 hours after infection and plating onto $7 \mathrm{H} 10$ agar plates.

Neutrophils were purified from buffy-coat as previously reported [15]. They were maintained on suspension in RPMI-1640 plus 5\% FBS. Neutrophils ( $10^{5}$ cells) were then infected with $M$. avium MAV_2043 KO or MAC104 wild type $\left(10^{5}\right.$ cells) for $30 \mathrm{~min}$ under constant rotation. After the neutrophils were centrifuged at $500 \mathrm{rpm}$ for $10 \mathrm{~min}$ and lysed to quantify viable intracellular bacteria. The eukaryotic cell lysate was plated onto 7H10 agar plates.

E. coli HB101, cultured in LB medium was used as control.

\section{Statistics}

Comparison between experimental groups was carried out using the Student's T test. A value of $\mathrm{p}<0.05$ was considered to be significant.

\section{Results and discussion}

\section{Comparison of protein extraction and affinity purification} buffers

Prior to initiating this study, several potential buffer components were tested for their capacity to solubilize mycobacterial proteins and their compatibility with the streptavidin-biotin affinity interaction. The results of these experiments indicated that both non-ionic detergents (Triton X-100 and Tween-20) and urea (7 M) were reasonably effective for total protein solubilization. However, this analysis also indicated that the concentrations of detergents and/or chaotropic reagents that yielded maximum protein solubilization were deleterious to the streptavidin-biotin affinity interaction. To resolve this conflict, we employed a strategy of protein extraction at high detergent/urea concentrations followed by dilution prior to affinity purification. In this study we evaluated two buffer mixtures that had shown promise in earlier testing, a detergent-based extraction buffer (DEB) and a urea-based extraction Buffer (UEB). Analysis of the protein extraction capacity of both of these buffers indicated that they were similarly effective at solubilizing total protein (Figure 1). With respect to the complement of proteins that were detected in each buffer condition, our analysis indicated that the large majority of the observed proteins were the same between both buffers (Figure 2A).

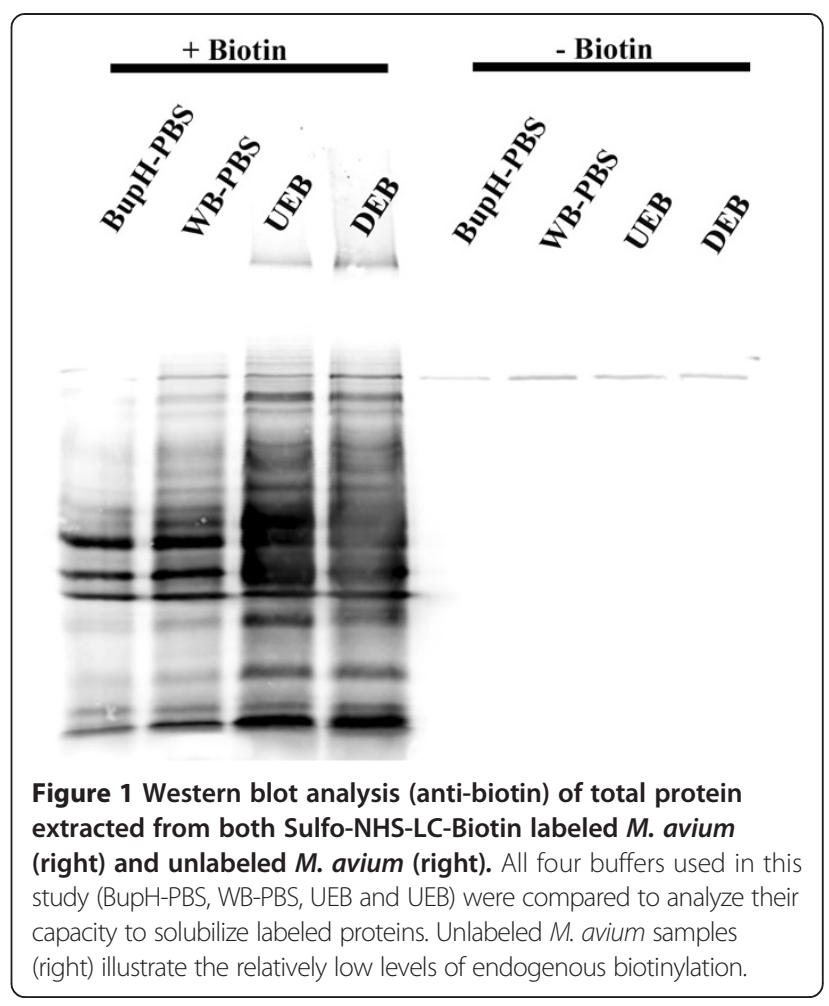

A

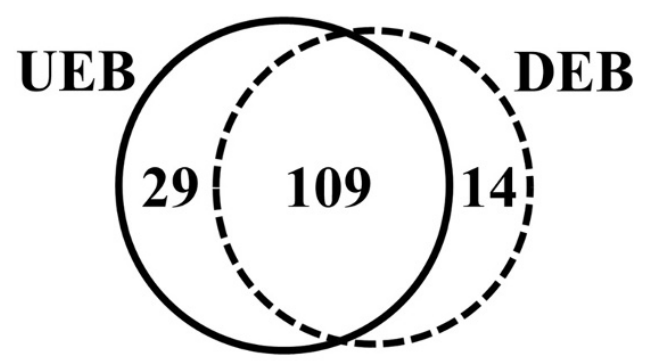

B

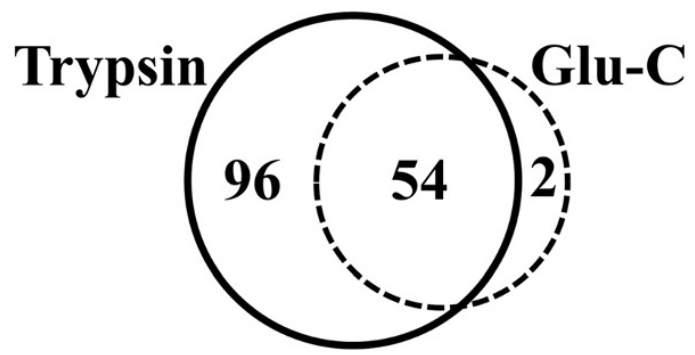

Figure 2 Venn diagram of proteins detected in each experimental condition. Values indicate total number of surface-exposed proteins detected in each experimental condition, with overlap indicating those proteins detected in both conditions. A. Comparison of extraction and purification buffers; surface proteins detected from samples extracted and purified with either Urea Extraction Buffer (UEB) or Detergent Extraction Buffer (DEB). B. Comparison of proteolytic enzymes; surface proteins detected from samples digested with either Trypsin or Glu-C proteases. 
Table 1 Virulence-associated proteins observed on the surface of M. avium 104

\begin{tabular}{lccc}
\hline Uniprot annotation & Accession & Gene & Reference \\
\hline Superoxide dismutase [Mn] & A0Q988_MYCA1 & MAV_0182 & {$[20]$} \\
Antigen 85A & A0Q9C0_MYCA1 & MAV_0214 & {$[21]$} \\
Antigen 85C & A0Q9C1_MYCA1 & MAV_0215 & {$[21]$} \\
ABC transporter dppD & A0QA11_MYCA1 & MAV_0467 & {$[22]$} \\
Lipoprotein LpqE & A0QAB1_MYCA1 & MAV_0569 & {$[23]$} \\
Mce family protein & A0QBC2_MYCA1 & MAV_0949 & {$[24]$} \\
Superoxide dismutase [Cu-Zn] & A0QEC3_MYCA1 & MAV_2043 & {$[25]$} \\
Wag31 protein & A0QF61_MYCA1 & MAV_2345 & {$[26]$} \\
Antigen 85B & A0QGG5_MYCA1 & MAV_2816 & {$[21]$} \\
ModD protein & A0QGK7_MYCA1 & MAV_2859 & {$[27]$} \\
NIpC/P60 family protein & A0QHK2_MYCA1 & MAV_3208 & {$[28]$} \\
LprG protein & A0QI11_MYCA1 & MAV_3367 & {$[29]$} \\
Protein export protein SecF & A0QIB1_MYCA1 & MAV_3467 & {$[30]$} \\
Protein export protein SecD & A0QIB2_MYCA1 & MAV_3468 & {$[30]$} \\
Heparin binding hemagglutinin & A0QLL5_MYCA1 & MAV_4675 & {$[31]$} \\
MVIN family protein & A0QNC0_MYCA1 & MAV_5298 & {$[32]$} \\
\hline & & & \\
\hline
\end{tabular}

\section{Comparison of trypsin and Glu-C proteolysis}

Trypsin, which cleaves after lysine and arginine residues, is the protease most commonly used to digest proteins into peptides for identification with mass spectrometry. However, several proteins that are known to be surfaceexposed in mycobacteria (e.g. many of the PPE and PE family proteins) are relatively lysine and arginine poor [16]. Because of this limitation, we hypothesized that the addition of an alternative proteolytic enzyme may be beneficial, increasing the number of identified proteins and the peptide coverage of those proteins. In this study, we compared the data generated by trypsin proteolysis with that generated by Glu-C proteolysis, which cleaves

Table 2 Type seven secretion system (T7SS) associated proteins observed on the surface of M. avium 104

\begin{tabular}{lccc}
\hline Uniprot annotation & Accession & Gene & T7SS Loci \\
\hline Uncharacterized protein & A0Q962_MYCA1 & MAV_0156 & ESX-2 \\
Conserved membrane protein & A0Q965_MYCA1 & MAV_0159 & ESX-2 \\
PPE family protein & A0QGQ3_MYCA1 & MAV_2905 & ESX-5 \\
PPE family protein & A0QGQ4_MYCA1 & MAV_2906 & ESX-5 \\
PPE family protein & A0QGQ7_MYCA1 & MAV_2909 & ESX-5 \\
PPE family protein & A0QGQ8_MYCA1 & MAV_2910 & ESX-5 \\
Uncharacterized protein & A0QGR5_MYCA1 & MAV_2917 & ESX-5 \\
Secretion protein & A0QGR7_MYCA1 & MAV_2919 & ESX-5 \\
PE family protein & A0QGS1_MYCA1 & MAV_2923 & ESX-5 \\
Uncharacterized protein & A0QGT1_MYCA1 & MAV_2933 & ESX-5 \\
PPE family protein & A0QKH6_MYCA1 & MAV_4274 & Unknown \\
Uncharacterized protein & A0QKS7_MYCA1 & MAV_4380 & ESX-4 \\
Serine esterase & A0QKU1_MYCA1 & MAV_4394 & ESX-4 \\
\hline
\end{tabular}

Table 3 Role of Cu-Zn SOD of M. avium in human monocyte-derived macrophage infection

\begin{tabular}{llll}
\hline & \multicolumn{3}{c}{ CFU/10 } \\
\hline Infection & $30 \mathrm{~min}$ & $1 \mathrm{~h}$ & $2 \mathrm{~h}$ \\
WT M. avium 104 & $3.4 \pm 0.3 \times 10^{4}$ & $2.8 \pm 0.4 \times 10^{4}$ & $2.9 \pm 0.2 \times 10^{4}$ \\
MAV_2043 KO M. & $3.4 \pm 0.4 \times 10^{4}$ & $2.9 \pm 0.2 \times 10^{4}$ & $2.9 \pm 0.4 \times 10^{4}$ \\
avium 104 & & & \\
E. coli HB101 & $6.1 \pm 0.3 \times 10^{4}$ & $8.5 \pm 0.3 \times 10^{3(1)}$ & $6.1 \pm 0.3 \times 10^{3(1)}$ \\
\hline
\end{tabular}

(1) $p<0.05$ compared to 30 min time point.

after glutamic acid residues (at $\mathrm{pH}$ 8). As expected, proteolysis with Glu-C generated fewer overall peptides, and the majority of the corresponding proteins were also identified in the trypsin samples (Figure 2B). However, the peptides generated by Glu-C digestion were highly complementary with those produced by trypsin digestion and significantly improved the peptide coverage of identified proteins. Additionally, several proteins that were lysine and arginine poor were uniquely identified by Glu-C analysis (Additional file 1: Table S1).

\section{Observed surface proteins}

Across all of the experimental conditions, a total of $152 \mathrm{pu}-$ tative surface-exposed proteins from $M$. avium 104 were detected (Additional file 1: Table S1). The vast majority of these proteins were detected in both experimental buffer systems, suggesting a similar complement of proteins were solubilized (Figure 2). As expected, many proteins with putative roles in the biogenesis of the mycomembrane were observed. A particularly interesting group of proteins are those that are thought to be directly associated with mycobacterial virulence (Table 1). Many of these proteins are conserved homologs of mycobacterial antigens that are known to be surface-exposed in other species of mycobacteria [8,17-19]. In fact, one of them, $\mathrm{Cu}-\mathrm{Zn}$ SOD is known to be a virulence associated protein in many pathogens but its role in mycobacteria has not been fully studied.

Another group of interesting proteins are those associated with the mycobacterial Type 7 Secretion System (T7SS), which is known to export a range of proteins necessary to mycobacterial virulence [33]. Mycobacterium avium has four loci that encode for distinct copies of this unique secretion system [16]. Furthermore, the secretion apparatus encoded by each locus is believed to

Table 4 Role of Cu-Zn SOD of M. avium in neutrophil infection

\begin{tabular}{lll}
\hline & \multicolumn{2}{c}{ CFU/10 $0^{5}$ neutrophil lysate } \\
\hline Infection & 30 min & $1 \mathrm{~h}$ \\
WT M. avium 104 & $4.3 \pm 0.4 \times 10^{3}$ & $4.6 \pm 0.3 \times 10^{3}$ \\
MAV_2043 KO M. avium 104 & $2.6 \pm 0.5 \times 10^{3}$ & $5.1 \pm 0.4 \times 10^{2(1)}$ \\
E. coli HB101 & $7.4 \pm 0.3 \times 10^{4}$ & $6.8 \pm 0.3 \times 10^{2(1)}$ \\
\hline
\end{tabular}

(1) $p<0.05$ compared with the number of bacteria at $30 \mathrm{~min}$. 
be responsible for the export of a relatively unique set of substrate proteins. This analysis detected evidence of structural proteins associated with three of the four ESX loci (Table 2). In addition, several putative substrate proteins from the PPE and PE protein families were also observed, although nearly all of these were associated with one ESX loci, ESX-5.

\section{Evaluation of the mutation in a surface protein, MAV_2043}

Monocyte derived macrophages were infected with the wild type and MAV_2043, and number of intracellular viable bacteria were determined after 1 and $2 \mathrm{~h}$. As shown in Table 3, the deficiency in MAV_2043 (Cu-Zn SOD) had a small effect on the survival of $M$. avium in macrophages. However, when the host cells were neutrophils, the absence of superoxide dismutase on the surface of $M$. avium was associated with significant decrease in bacterial viability (Table 4).

Our results with $M$. avium resembles the results obtained with Mycobacterium tuberculosis and macrophages [34] in which the deficiency of $\mathrm{Cu}-\mathrm{Zn}$ SOD led to a small decrease in the ability to survive although the authors did not evaluate the interaction between $M$. tuberculosis and neutrophils. The study also adds to previous observation that neutrophils can kill M. avium in vivo $[15,34,35]$ and seem to be part of the effective innate response against $M$. avium [15,36]. Neutrophils are capable of producing and releasing increasing amounts of superoxide anion than macrophages. During virulent $M$. avium infection, neutrophils appear to be important, but their role is only in the initial phase of the infection, which suggests that $M$. avium avoids them and preferentially infects macrophages (observation not shown). Recently, we demonstrated that $M$. avium, when phagocytosed by macrophages, expresses additional proteins in the surface [37], but MAV_2043 is observed on the surface even before contact with phagocytic cells.

\section{Potential contaminants}

A number of proteins were detected that are possible contaminants, including ribosomal proteins, DNA gyrase and other nucleotide binding proteins (Additional file 1: Table S1). Although nucleotide proteins have been previously observed in the mycomembrane and at the surface of several species of Mycobacterium, these proteins may indeed represent persistent contaminants $[18,38,39]$. Because nucleotide binding proteins tend to have abundant arginine and lysine residues, they are excellent substrates for trypsinbased digestion. Additionally, contaminating DNA may cause many of these proteins to be non-specifically coprecipitated along with labeled proteins. Ultimately, the proteins detected in this study should be considered a preliminary profile, pending the independent confirmation of these observations with complementary methods.

\section{Conclusions}

The selective biotinylation of surface-exposed proteins using membrane impermeable reagents has become an important tool in the study of this subset of the cellular proteome. This study adapted the aforementioned method to investigate the surface proteins $M$. avium 104. We demonstrated the feasibility of this specific approach by characterizing the surface proteome of a reference strain of $M$. avium 104. We also confirmed the important role of one of the surface associated proteins, $\mathrm{Cu}-\mathrm{Zn}$ superoxide dismutase While its participation on macrophage infection was limited, its value to $M$. avium upon infection of neutrophils, what happens during the initial phase of the infection in vivo [15], was significant. The method used for determination of surface proteome then can identify important virulence factors in bacterial pathogens.

\section{Ethical approval}

The research reported was approved by the University Biosafety Committee.

\section{Additional file}

\section{Additional file 1: Figure S1. List of M. avium surface proteins obtained by Mass-Espec.}

\section{Competing interests}

The authors declare that there are no competing interests.

\section{Authors' contributions}

MMcN: Design, perform experiments, analyzed results, wrote the paper. S-CT: Perfom proteome assays, analyzed results. CM: Perform proteome assays, analyzed results. MW: Evaluated the mutants. LEB: Design experiments, analyzed results, edited the paper. All authors read and approved the final manuscript.

\section{Acknowledgements}

We thank Denny Weber for editing and Beth Chamblin for typing the manuscript. We also thank Yong Li for sequencing the mutant. The research was supported by the NIH grant \# Al43199.

\section{Funding}

National Institutes of Health Grant Al-41399.

\section{Author details}

'Department of Biomedical Sciences, Molecular and Cellular Biology Program, Corvallis, USA. ${ }^{2}$ Department of Microbiology, Corvallis, USA. ${ }^{3}$ Department of Chemistry, Corvallis, USA. ${ }^{4}$ Oregon State University, Corvallis, Oregon 97331-4801, USA.

Received: 8 March 2013 Accepted: 17 November 2013 Published: 28 November 2013

\section{References}

1. Horsburgh CR Jr: Mycobacterium avium complex infection in the acquired immunodeficiency syndrome. N Engl J Med 1991, 324:1332-1338.

2. Carter G, Wu M, Drummond DC, Bermudez LE: Characterization of biofilm formation by clinical isolates of Mycobacterium avium. J Med Microbiol 2003, 52:747-752.

3. Bermudez LE, Young LS: Factors affecting invasion of HT-29 and HEp-2 epithelial cells by organisms of the Mycobacterium avium complex. Infect Immun 1994, 62:2021-2026. 
4. Early J, Fischer K, Bermudez LE: Mycobacterium avium uses apoptotic macrophages as tools for spreading. Microb Pathog 2010, 50:132-139.

5. Lin J, Huang S, Zhang Q: Outer membrane proteins: key players for bacterial adaptation in host niches. Microbes Infect 2002, 4:325-331.

6. Lindahl G, Stalhammar-Carlemalm M, Areschoug T: Surface proteins of Streptococcus agalactiae and related proteins in other bacterial pathogens. Clin Microbiol Rev 2005, 18:102-127.

7. Hughes V, Bannantine JP, Denham S, Smith S, Garcia-Sanchez A, Sales J, Paustian ML, McLean K, Stevenson K: Immunogenicity of proteome-determined Mycobacterium avium subsp. paratuberculosis-specific proteins in sheep with paratuberculosis. Clin Vaccine Immunol 2008, 15:1824-1833.

8. Li Y, Zeng J, Shi J, Wang M, Rao M, Xue C, Du Y, He ZG: A proteome-scale identification of novel antigenic proteins in Mycobacterium tuberculosis toward diagnostic and vaccine development. J Proteome Res 2010, 9:4812-4822.

9. Elia G: Biotinylation reagents for the study of cell surface proteins. Proteomics 2008, 8:4012-4024.

10. Lu B, McClatchy DB, Kim JY, Yates JR 3rd: Strategies for shotgun identification of integral membrane proteins by tandem mass spectrometry. Proteomics 2008, 8:3947-3955

11. Tjalsma H, Lambooy L, Hermans PW, Swinkels DW: Shedding \& shaving: disclosure of proteomic expressions on a bacterial face. Proteomics 2008 8:1415-1428.

12. Alsteens D, Verbelen C, Dague E, Raze D, Baulard AR, Dufrene YF: Organization of the mycobacterial cell wall: a nanoscale view. Pflugers Arch 2008, 456:117-125.

13. Li Y, Miltner E, Wu M, Petrofsky M, Bermudez LE: A Mycobacterium avium PPE gene is associated with the ability of the bacterium to grow in macrophages and virulence in mice. Cell Microbiol 2005, 7:539-548.

14. Wagner D, Sangari FJ, Kim S, Petrofsky M, Bermudez LE: Mycobacterium avium infection of macrophages results in progressive suppression of interleukin-12 production in vitro and in vivo. J Leukoc Biol 2002, 71:80-88.

15. Petrofsky M, Bermudez LE: Neutrophils from Mycobacterium aviuminfected mice produce TNF-alpha, IL-12, and IL-1 beta and have a putative role in early host response. Clin Immunol 1999, 91:354-358.

16. Gey van Pittius NC, Sampson SL, Lee H, Kim Y, Van Helden PD, Warren RM: Evolution and expansion of the Mycobacterium tuberculosis PE and PPE multigene families and their association with the duplication of the ESAT-6 (esx) gene cluster regions. BMC Evol Biol 2006, 6:95

17. Beatty WL, Russell DG: Identification of mycobacterial surface proteins released into subcellular compartments of infected macrophages. Infect Immun 2000, 68:6997-7002

18. He Z, De Buck J: Localization of proteins in the cell wall of Mycobacterium avium subsp. paratuberculosis $\mathrm{K} 10$ by proteomic analysis. Proteome Sci 2010, 8:21.

19. Marques MA, Chitale S, Brennan PJ, Pessolani MC: Mapping and identification of the major cell wall-associated components of Mycobacterium leprae. Infect Immun 1998, 66:2625-2631.

20. Braunstein M, Espinosa BJ, Chan J, Belisle JT, Jacobs WR Jr: SecA2 functions in the secretion of superoxide dismutase $A$ and in the virulence of Mycobacterium tuberculosis. Mol Microbiol 2003, 48:453-464.

21. Harth G, Horwitz MA, Tabatadze D, Zamecnik PC: Targeting the Mycobacterium tuberculosis 30/32-kDa mycolyl transferase complex as a therapeutic strategy against tuberculosis: proof of principle by using antisense technology. Proc Natl Acad Sci USA 2002, 99:15614-15619.

22. Danelishvili L, Poort MJ, Bermudez LE: Identification of Mycobacterium avium genes up-regulated in cultured macrophages and in mice. FEMS Microbiol Lett 2004, 239:41-49.

23. Roux AL, Ray A, Pawlik A, Medjahed H, Etienne G, Rottman M, Catherinot E, Coppee JY, Chaoui K, Monsarrat B, Toubert A, Daffe M, Puzo G, Gaillard JL, Brosch R, Dulphy N, Nigou J, Herrmann JL: Overexpression of proinflammatory TLR-2-signalling lipoproteins in hypervirulent mycobacterial variants. Cell Microbiol 2010, 13:692-704

24. Gioffre A, Infante E, Aguilar D, Santangelo MP, Klepp L, Amadio A, Meikle V, Etchechoury I, Romano MI, Cataldi A, Hernandez RP, Bigi F: Mutation in mce operons attenuates Mycobacterium tuberculosis virulence. Microbes Infect 2005, 7:325-334.

25. Piddington DL, Fang FC, Laessig T, Cooper AM, Orme IM, Buchmeier NA: $\mathrm{Cu}, \mathrm{Zn}$ superoxide dismutase of Mycobacterium tuberculosis contributes to survival in activated macrophages that are generating an oxidative burst. Infect Immun 2001, 69:4980-4987.
26. Mukherjee $P$, Sureka K, Datta P, Hossain T, Barik S, Das KP, Kundu M, Basu J: Novel role of Wag31 in protection of mycobacteria under oxidative stress. Mol Microbiol 2009, 73:103-119.

27. Ragas A, Roussel L, Puzo G, Riviere M: The Mycobacterium tuberculosis cell-surface glycoprotein apa as a potential adhesin to colonize target cells via the innate immune system pulmonary C-type lectin surfactant protein A. J Biol Chem 2007, 282:5133-5142.

28. Gao LY, Pak M, Kish R, Kajihara K, Brown EJ: A mycobacterial operon essential for virulence in vivo and invasion and intracellular persistence in macrophages. Infect Immun 2006, 74:1757-1767.

29. Bigi F, Gioffre A, Klepp L, Santangelo MP, Alito A, Caimi K, Meikle V, Zumarraga M, Taboga O, Romano MI, Cataldi A: The knockout of the IprGRv1410 operon produces strong attenuation of Mycobacterium tuberculosis. Microbes Infect 2004, 6:182-187.

30. Converse SE: A protein secretion pathway critical for Mycobacterium tuberculosis virulence is conserved and functional in Mycobacterium smegmatis. J Bacterio/ 2005, 187:1238-1245.

31. Sechi LA, Ahmed N, Felis GE, Dupre I, Cannas S, Fadda G, Bua A, Zanetti S: Immunogenicity and cytoadherence of recombinant heparin binding haemagglutinin (HBHA) of Mycobacterium avium subsp. paratuberculosis: functional promiscuity or a role in virulence? Vaccine 2006, 24:236-243.

32. Davis FP, Barkan DT, Eswar N, McKerrow JH, Sali A: Host pathogen protein interactions predicted by comparative modeling. Protein Sci 2007, 16:2585-2596

33. Abdallah AM, Gey van Pittius NC, Champion PA, Cox J, Luirink J, Vandenbroucke-Grauls CM, Appelmelk BJ, Bitter W: Type VII secretionmycobacteria show the way. Nat Rev Microbiol 2007, 5:883-891.

34. Buchmeier N, Blanc-Potard A, Ehrt S, Piddington D, Riley L, Groisman EA: A parallel intraphagosomal survival strategy shared by mycobacterium tuberculosis and Salmonella enterica. Mol Microbiol 2000, 35:1375-1382.

35. Dussurget O, Stewart G, Neyrolles O, Pescher P, Young D, Marchal G: Role of Mycobacterium tuberculosis copper-zinc superoxide dismutase. Infect Immun 2001, 69:529-533

36. Appelberg R, Castro AG, Gomes S, Pedrosa J, Silva MT: Susceptibility of beige mice to Mycobacterium avium: role of neutrophils. Infect Immun 1995, 63:3381-3387.

37. McNamara M, Tzeng SC, Maier C, Zhang L, Bermudez LE: Surface proteome of "Mycobacterium avium subsp. hominissuis" during the early stages of macrophage infection. Infect Immun 2012, 80:1868-1880.

38. He Z, De Buck J: Cell wall proteome analysis of Mycobacterium smegmatis strain MC2 155. BMC Microbiol 2010, 10:121.

39. Sani M, Houben EN, Geurtsen J, Pierson J, De Punder K, Van Zon M, Wever B, Piersma SR, Jimenez CR, Daffe M, Appelmelk BJ, Bitter W, van der Wel N, Peters PJ: Direct visualization by cryo-EM of the mycobacterial capsular layer: a labile structure containing ESX-1-secreted proteins. PLOS Pathog 2008, 6:e1000794.

doi:10.1186/1477-5956-11-45

Cite this article as: McNamara et al: Surface-exposed proteins of pathogenic mycobacteria and the role of cu-zn superoxide dismutase in macrophages and neutrophil survival. Proteome Science 2013 11:45.

\section{Submit your next manuscript to BioMed Central and take full advantage of:}

- Convenient online submission

- Thorough peer review

- No space constraints or color figure charges

- Immediate publication on acceptance

- Inclusion in PubMed, CAS, Scopus and Google Scholar

- Research which is freely available for redistribution 